\title{
O Papel das Pesquisas de Opinião Pública na Consolidação da Democracia:
}

a experiência latino-americana

\section{Fabián Echegaray}

Professor Visitante da Universidade Federal de Santa Catarina

\begin{abstract}
Resumo
Desde inícios dos anos 80 , as pesquisas políticas e de opinião pública na América Latina têm se constituído num evento central ao processo de democratização. Quase todos os dias, os principais jornais e redes de TV da cada país nos informam sobre estudos focados sobre assuntos vinculados ao desenvolvimento político das novas democracias. Grande parte do que conhecemos sobre essas instituições é produto de pesquisas. Mas, qual têm sido as conseqüências disso? Este artigo mostra que essas pesquisas definem interações centrais entre elites políticas e cidadania nesses países, e que têm um papel central no seus processos de democratização.
\end{abstract}

Palavras-chave: opinião pública, pesquisas de opinião, processo de democratização, América Latina

\begin{abstract}
Since the beginning of the eighties the political surveys in Latin America have a central role in the process of democratization. Almost everyday the main newspapers and tv broadcastings of each country inform us the results of studies that focuses on the political development of the new democracies. Most of what we know about these democracies is due to these studies. But what are the consequences of this role? This article argues that the public opinion surveys define central interactions between the political elites and the citizenship in these countries, and that they have a central role in their democratization processes.
\end{abstract}

Key-words: public opinion, survey research, democratization process, Latin América 
Desde inícios dos anos 80, as pesquisas políticas e de opinião pública na América Latina têm se constituído num evento central ao processo de democratização. Quase todos os dias, os principais jornais e redes de TV de cada país nos informam sobre estudos focados em assuntos da maior relevância pública ou estreitamente vinculados ao desenvolvimento político das novas democracias. Assim, quanto mais comuns tornam-se as instituições democráticas, mais intensa é a presença das pesquisas de opinião.

Grande parte do que conhecemos sobre essas instituições, seus "comos e porquês", são produto de pesquisas; um bom número das informações que os cidadãos e políticos utilizam para dizer o que está certo e o que está errado no governo democrático também tem sua origem nas pesquisas. $E$ também não é estranho que muitas das iniciativas que marcam a agenda pública do dia-a-dia se relacionem com resultados e interpretações surgidos de pesquisas políticas e de opinião.

A centralidade desses estudos, portanto, é um fato na maioria dos nossos países. Mas, qual têm sido as conseqüências disso? Qual tem sido o papel destas pesquisas ao longo do processo de democratização da região? Como é que estes estudos moldaram as interações entre elites políticas e a cidadania em geral?

Nossa intenção aqui é discutir a experiência latino-americana à luz de alguns exemplos concretos. E para tal, a reflexão acumulada em outros contextos democráticos como os dos Estados Unidos, pioneiros no uso e desenvolvimento dos mecanismos de pesquisa política, é fundamental na hora de organizar tal discussão.

\section{As duas faces das pesquisas}

Desde seu surgimento como ferramenta fundamental de conhecimento, o papel das pesquisas tem sido tanto elogiado como demonizado com relação ao seus efeitos sobre o progresso e governo democráticos. Nascidas junto com o otimismo do George Gallup (1940), para quem as pesquisas contribuíram para um governo mais democrático, eficiente e responsável, as pesquisas não demoraram em se confrontar com o cinismo inicial de Walter Lippman (1925) para quem o público estava ausente na elaboração de opiniões genuínas e com conseqüências políticas. Daí a dizer que as pesquisas poderiam estar sujeitas à manipulação pelas elites foi preciso pouco, levando a controvérsia adiante.

Em termos gerais, os argumentos que enfatizam o lado positivo das pesquisas nos falam da sua contribuição para aproximar os interesses e opiniões de representados e representantes, seu estímulo para um tipo de fiscalização pública da conduta e decisões políticas das lideranças, a possibilidade de dar continuidade à voz pública dos cidadãos além do período eleitoral, e a oportunidade de aumentar a qualidade da informação sobre a qual são tomadas determinadas decisões de governo. Tal como um dos primeiros comentaristas de pesquisas manifestou: "os estudos de opinião pública dão ao povo a chance de se expressar" (Cherington, 1940). 
Além destas vantagens, as pesquisas também são vistas como contendo propriedades pedagógicas e terapêuticas pelo fato de induzir um processo de autoconhecimento e um aprendizado informado sobre noções e conceitos populares vitais.

Do lado negativo, as pesquisas são vistas como distorcendo o espírito de representação das instituições democráticas ao tornar trivial o papel das eleições e promover uma liderança irresponsiva. Elas são acusadas de ilustrar uma caricatura das preferências cidadãs já que ignoram a verdadeira dinâmica de formação e mudança da opinião, minimizando as influências dos líderes, da mídia e dos grupos de interesses na construção de respostas por parte da população. Tal situação acaba enganando os cidadãos ao Ihes transmitir um senso falso de influência quando na verdade o poder de opinião é exercido por uma elite que pode, ou não, estar agindo em nome do interesse público. A conseqüência disso é reduzir a opinião pública cidadã a um participante de enquetes políticas passivo e domesticado, cujas opiniões são previamente limitadas em função das opções de respostas pré-estabelecidas pelas elites (Guinsberg, 1986; McGuire, 1940). Um exemplo típico é a lista de principais problemas do país ou principais objetivos do governo, apresentados como a agenda do público quando muitas vezes só ilustra as opções de resposta escolhidas pelos patrocinadores do estudo. É através deste tipo de situações que as pesquisas se apresentam antes como instrumentos potenciais dos interesses retóricos das elites do que como oportunidades autênticas para a expressão das maiorias silenciosas (Herbst, 1993). Sob este ponto de vista, as pesquisas obstruem a discussão pública ao invés de estimulá-la.

Mais recentemente, em especial em períodos pré-eleitorais, multiplicaram-se as acusações contra pesquisas publicadas sob o argumento que as mesmas estariam influenciando os votantes. Também muito freqüentemente, ocorreram denúncias contra o uso especulativo de pesquisas encomendadas por agentes de bolsa e políticos, para benefício privado, resultante de restrições legais de difusão pública dos resultados (Kavannah, 1981; Worcester, 1993).

Outra acusação corrente diz que, produto das necessidades comerciais e de marketing, a mídia trocou seu compromisso original de aprofundar a opinião pública baseada na divulgação de resultados sobre assuntos relevantes, pela banalização da própria opinião através de pesquisar tópicos marginais ou ficar apenas na superfície das respostas. Como resultado, foi abortada a tentativa de avançar na democratização da esfera pública a partir dos meios de comunicação. Assim, em lugar de um uso educativo das técnicas de sondagem política, a mídia tende a inventar assuntos considerados capazes de atrair a atenção do público e dos anunciantes, estimulando um círculo no qual ela paga por pesquisas feitas sobre tópicos selecionados, para depois divulgar seus resultados como se fossem eventos do mundo real e, assim, forçar a entrada destes na agenda de interesse público. Este modelo vertical de modelagem da agenda é bem provável que seja adequado às necessidades políticas e comerciais da mídia, mas fica longe de ajudar ao progresso da democracia (Zukin, 1992; Donsbach, 1995). 
Muitos desses argumentos combinam perfeitamente com o uso que na América Latina tem-se feito das pesquisas políticas. Porém, o caráter heterogêneo do processo de democratização na região e os diferentes caminhos que levaram ao surgimento da pesquisa política em cada país sugerem olhar, também, para outras questões. Ao nosso ver, são 4 as dimensões relevantes:

a) como as elites entendem e dão sentido ao significado e à informação fornecidos pelas pesquisas,

b) o grau de legitimidade política (isto é, neutralidade) com o qual as pesquisas são percebidas,

c) a medida na qual a mídia nacional é livre, plural e tem um interesse ativo em tornar-se um espaço de difusão da opinião pública,

d) como as noções populares sobre democracia concebem o papel do próprio público (se substantivo ou irrelevante) e o grau de cinismo ou confiança que subjaz às atitudes das pessoas com respeito aos veículos de expressão públicos e privados (incluindo aí a mídia e as pesquisas).

Estas dimensões, por sua vez, nos permitem organizar a discussão sobre o papel político das pesquisas de opinião pública, examinando o efeito que elas têm sobre:

a) a melhora da representação política da sociedade (ou, qual seu impacto em fazer progredir o interesse público sob condições democráticas?). Em outras palavras, examinar a contribuição das pesquisas para uma melhor comunicação entre elites e público de massa, para facilitar o aprendizado político no nível das elites no que diz respeito às oportunidades para construção de consensos e acordos de governabilidade, para moldar um debate mais educado sobre políticas específicas, para fazer a agenda política mais permeável a novas demandas e assuntos, e para aproximar as decisões dos líderes às preferências da população;

b) o fortalecimento das oportunidades e instituições democráticas (ou, até que grau e de que forma as pesquisas têm impactado sobre os líderes e a cidadania de forma a contribuir com a regularização e legitimação das rotinas democráticas?). Em outras palavras, examinar os usos das pesquisas na promoção da liberalização política e no cumprimento das promessas eleitorais dos governos autoritários, na prevenção de fraudes, no desestímulo à formação de apoio a golpes ou intervenções extra-legais dentro da democracia, no estímulo a uma maior pluralização e transparência da vida partidária e da seleção dos candidatos a cargos políticos, na redução do clientelismo e coronelismo e o conseqüente aumento das iniciativas cidadãs e expressões organizadas da sociedade civil;

c) a legitimação das opções antidemocráticas (ou, como o uso das pesquisas políticas tem enfraquecido as lideranças e instituições democrática e facilitado o fortalecimento de políticas e opções autoritárias?). Ou seja, examinar os 
usos das pesquisas em defesa de políticas contrárias ao pluralismo, ao respeito das minorias, ou em favor da desmobilização de grupos e valores políticos chaves para a democracia, ou como meios de legitimar o apoio para ações internas anticonstitucionais (ex: governar mediante medidas provisórias, fechar o Congresso, tentativas ou golpes de Estado, etc) ou para atividades externas em favor de soluções autoritárias a problemas internos (ex: guerra com outros países).

\section{Quando as pesquisas contribuem para maior representação política}

O potencial das pesquisas na melhoria da representação política do público tem sido um dos primeiros atributos adjudicados a elas, em primeiro lugar pelos fundadores da técnica de sondagem, George Gallup (Gallup e Rae, 1940; Cantril, 1967). Notavelmente, esse mesmo otimismo pode ser identificado nos poucos estudos publicados sobre a região. Tal como comenta Bolívar Lamounier (1992, p.5) na sua introdução ao desenvolvimento da pesquisa no Brasil: "Elas contribuem efetivamente para o autoconhecimento da sociedade. Por meio delas o cidadão se expressa sobre a agenda corrente da sociedade; reage às políticas governamentais que exercem impacto sobre sua vida; estabelece parâmetros para a ação das organizações públicas e privadas, e não raro influencia decisões importantes".

A dimensão desta noção das pesquisas como capazes de materializar um "bem público" para a sociedade como um todo vai além das crenças dos cientistas políticos e pesquisadores. Isso fica em evidência através de diferentes iniciativas. Uma delas foi o chamado Projeto Leader no Brasil, o qual visava melhorar a comunicação entre os candidatos a presidentes em 1989 e o eleitorado e que fora financiado pela FIESP. Mais recentemente, também no Brasil, iniciativas regulares da Confederação Nacional das Indústrias (CNI) e do Transporte (CNT) procuram, entre outros objetivos, informar sobre o estado da opinião pública e a distância ou proximidade entre o comportamento das autoridades eleitas e seus eleitores. Na mesma direção devemos interpretar uma iniciativa tomada no Peru, meses antes da eleição legislativa de 1992, quando o Congresso encomendou o relatório Datum visando coletar dados e recomendações sobre sua imagem pública e os temas a priorizar para recuperar a confiança da população.

Este aporte potencial das pesquisas à causa democrática também é reconhecido por Garretón e seus colegas (1993) no seu trabalho sobre as atitudes políticas dos chilenos. Ali, eles enfatizam a função das pesquisas em detectar os déficits e fraquezas que impedem a plena legitimação do sistema e em alertar o Estado, as universidades ou as entidades não-governamentais sobre como corrigir e reverter tais defeitos mediante a educação das autoridades e o desenvolvimento de oportunidades de engajamento coletivo e canais de comunicação com os que tomam decisões. Mais ainda, eles 
concordam que as pesquisas têm o potencial de ajudar a reduzir o número de erros no processo de tomada de decisões, capazes de gerar mais insatisfação, enriquecendo com informações o processo decisório.

De fato, checar a evidência empírica sobre a qualidade da representação política, em termos da correspondência entre posições dos líderes e seus representados, tem sido uma das áreas clássicas de estudo da ciência política (Miller e Stokes, 1963, Page et al., 1984; Herrera et al., 1993). A maioria destes esforços concentraram-se na análise do vínculo entre as preferências por políticas e as prioridades temáticas das elites e o público: quanto maior congruência entre umas e outras, melhor a qualidade da representação política. Infelizmente, este tipo de estudo ainda não foi reproduzido no contexto latino-americano. Só algumas explorações bastante gerais podem ser encontradas para o Brasil e estão vinculadas ao debate entre presidencialismo ou parlamentarismo que animou a primeira metade da década de 90. Lamounier (1994, pp.289-290) exibe um análise que parcialmente indica certa congruência entre elites e massas, embora a mesma demonstre que os resultados destes estudos serviram melhor para que os grupos partidários do presidencialismo identificassem os argumentos mais populares a suas opiniões. Um caso similar se deu no Uruguai, já em relação ao plebiscito sobre privatização das empresas públicas que teve lugar em 1992. Ali, mesmo que as elites tenham tecido um acordo favorável à desestatização em várias áreas, a oposição pública expressada através das enquetes de opinião não passou despercebida, estimulando líderes contrários à decisão do governo a mobilizar a população num referendum, que teve como resultado o cancelamento do programa de privatização (McCoy, 1995).

Muitos jornalistas e acadêmicos na região têm olhado para as pesquisas como instrumentos necessários para fiscalizar as ações (e omissões) das autoridades. Os casos mais ressonantes estiveram vinculados às denúncias de corrupção que acabaram no impeachment dos presidentes Fernando Collor de Mello no Brasil e Carlos Pérez na Venezuela. Em ambas as ocasiões ocorreu um ciclo virtuoso de pesquisas mostrando o descontentamento com os comportamentos das autoridades, que facilitaram a mobilização popular de protesto em favor de punições, as quais - por sua vezinfluenciaram na colocação da questão da corrupção no topo das preocupações do público (como fora registrado pelas próprias pesquisas), o que acabou, em última instância, por pressionar as instituições democráticas a tornar-se mais responsáveis e atentas às demandas cidadãs (Scott, 1993).

Outro ponto de consenso sobre o papel positivo das pesquisas tem a ver com suas interações com o processo eleitoral. É uma suposição comprovada em diversos contextos que os estudos bem desenhados fornecem aos candidatos conhecimento essencial não apenas para competir eleitoralmente mas também para tomar decisões informadas uma vez no poder (Kavannah, 1981). Isso não equivale a dizer que as pesquisas definem a agenda pública (algo também comprovado pela evidência empírica), 
mas sim é consistente com a noção de que as pesquisas induzem mudanças importantes na hierarquia dos assuntos levantados como bandeiras pelos candidatos. Portanto, as pesquisas podem não alterar o tipo de palavras de ordem escolhidas pelos candidatos, mas têm sim uma influência decisiva em definir a saliência e ranking que determinados assuntos relevantes terão na agenda dos concorrentes (Altschuler, 1982, pp.171-173). De modo tal que pode se dizer que as pesquisas facilitam a função das eleições como canais que conectam as políticas oficiais aos desejos dos votantes e permitem certa premiação ou punição das autoridades pelas suas ações.

Por outro lado, como também tem acontecido na região, existem candidatos que dão atenção às pesquisas com olhar imediatista e de modo essencialmente utilitarista, visando apenas maximizar suas chances eleitorais mediante a adaptação do seu discurso e a segmentação oportunista dos eleitorados. Na medida em que se difunde esse perfil parece legítimo nos perguntarmos se as pesquisas afinal não servem apenas às estratégias individuais dos competidores eleitorais em troca da frustração do verdadeiro propósito das eleições.

Igualmente preocupante foi o consenso, entre alguns intelectuais, de que as pesquisas de opinião pública acabariam corporizando a representação política dos cidadãos substituindo a classe política sem capacidades para acompanhar os interesses flutuantes e as prioridades dos votantes.

\section{Quando as pesquisas contribuem para melhorar a qualidade da democracia}

Não menos destacado no caso latino-americano é o argumento que vê as pesquisas (particularmente as de boca de urna ou exit polls) como veículos chave para checar a limpeza do voto e desencorajar a fraude eleitoral. Acomodando-se à ansiedade da própria mídia em ter a "notícia quente" antes de qualquer um, as pesquisas de boca de urna acabam multiplicando as fontes de validação dos cômputos oficiais e garantem uma imediata transparência e prestação de contas por parte das autoridades eleitorais. As pesquisas tornam-se, assim, um teste de confiabilidade na honestidade das eleições (Leite \& Smith, 1992; Beltrán, 1994), tal como ficou testemunhado nas experiências de México e República Dominicana em 1994 e, mais recentemente, na terceira re-eleição de Alberto Fujimori no Peru.

Em casos como os da Argentina e Venezuela, a ampla difusão pública dos resultados das pesquisas através da mídia foi essencial para o fracasso de várias tentativas de golpe. Mas é correto dizer que, em algumas oportunidades, também ocorreu o contrário: isto é, quando achados de estudos de opinião funcionaram como miragens para forças antidemocráticas, motivando-as a deslanchar rebeliões militares, disseminar a violência política na rua ou mobilizar campanhas favoráveis à causas autoritárias. No caso da Venezuela, por exemplo, pesquisas difundidas no início e meados de 1992 indicando 
um profundo descrédito nas instituições básicas da democracia e seus líderes, foram interpretadas como via livre para uma mudança forçada do sistema, inspirando as insurreições dos oficiais " bolivarianos" em Fevereiro e Novembro daquele ano (Carrasquero \& Cupolo, 1992). O discurso rebelde enfatizando "o resgate da venezuelanidade e a renovação da democracia do país" esteve diretamente inspirada na lógica por detrás das respostas às sondagens de opinião publicadas. Os insurrectos sugeriram em mais de uma ocasião que seus atos estavam respaldados no descontentamento popular contra o governo, tal como manifesto pelas pesquisas. Mais ainda, a simpatia com que uma parcela importante da cidadania viu o complô de Fevereiro 1992 (novamente revelada pelas enquetes), saudados não como antidemocratas mas como falidos cruzados anticorrupção, parece ter alimentado a segunda tentativa, 9 meses depois (Carrasquero \& Cupolo, 1992).

Mas é verdade que a democracia venezuelana sobreviveu duas vezes num ano e as ameaças de uma terceira tentativa de golpe ficaram reduzidas apenas a boatos. Ainda mais, o sistema permitiu que o líder dos golpistas assumisse sua condição de chefe político de uma facção e triunfasse nas urnas como presidente eleito, 6 anos depois. $E$ isso também foi visto como derivação do que sugeriam as pesquisas: "as percepções negativas sobre as instituições democráticas tradicionais não conduziam à aprovação de um golpe de estado militar" (Myers, 1993, p.68). As pesquisas revelavam uma profunda desconfiança das autoridades e partidos tradicionais, uma necessidade de uma radical reparação no sistema político vigente, mas também uma preferência majoritária pela conservação das rotinas da democracia por sobre qualquer outro modelo de organização da autoridade e o poder. De fato, dois terços do eleitorado ainda aprovavam aspectoschaves como liberdade de expressão, pluralismo político, separação de poderes e voto universal. Tal como Welsch e Carrasquero (1995, pp.4-5) comentam: "que a democracia na Venezuela não tenha sido derrubada obedece a habilidade do público em distinguir entre regime político e o governo ou seus governantes".

Outra perspectiva a partir da qual são examinadas as pesquisas enfatiza sua contribuição pedagógica e terapêutica. Iniciada pelo padre Ignacio Martín-Baró e cristalizada no Instituto Universitário da Opinião Pública da Universidade Católica de El Salvador, esta visão vê nas pesquisas um canal de autoconhecimento e feedback responsivo à sociedade sobre si mesma. Numa nação onde as forças políticas justificaram contínuos atos de violência e a substituição de governos eleitos por ditaduras, sob a desculpa da falta de opções legítimas e a facilidade com que a população era enganada ou corrompida, o fato das pesquisas indicarem uma confiança majoritária nas virtudes da democracia, a paz e a autonomia nacional teve um efeito reparador fundamental. Por outro lado, as pesquisas também tiveram um papel importante em desvendar para a população os verdadeiros custos de uma restauração democrática, desmistificando o discurso ditatorial (e, às vezes, as impressões alimentadas na população) sobre o exagerado preço a pagar pela volta a um regime de governo eleito e civil. 
Nesse contexto de incertezas, durante a complicada década dos 80 , a criação de um meio de comunicação e divulgação dos resultados (o periódico Estudos Centroamericanos) culminou o esforço do grupo do IUDOP em viabilizar uma fonte independente de expressão e educação. Ao entender a pesquisa da opinião pública como um instrumento promotor da autoconsciência e da eficácia política subjetiva, Martín-Baró (1985) popularizou a noção da técnica de sondagem como um espelho colocado frente à população para validar o próprio senso comum das pessoas ${ }^{1}$.

\section{Quando as pesquisas deslegitimam opções não democráticas}

Outra situação na qual as pesquisas ajudaram a revelar realidades inventadas a partir do discurso oficial aconteceu na redemocratização do Panamá por forças externas, em princípios de 1990. Apoiando-se em pesquisas feitas no país pelas redes de TV e jornais dos EUA, logo após a invasão, que mostravam um forte respaldo local (quase $90 \%$ !) para a ação militar que tirou ao General Noriega do poder, o governo do presidente Bush considerou sua iniciativa como amplamente aceita. $O$ endosso à ação militar foi tal que a administração republicana não duvidou em disseminar ativamente os resultados das enquetes. Com elas se desqualificou quem criticou a invasão por motivos políticos como também as acusações sobre a escalada de mortes que a ação promoveu. Mas, as perguntas sobre a popularidade da operação militar eram só parte dos questionários. Neles também se interpelava sobre questões mais diretamente ligadas aos custos humanos e morais da intervenção e que pôs em perspectiva a posição oficial sobre o evento. Entre as perguntas feitas se perguntava aos panamenhos se algum parente ou amigo íntimo tinha morrido ou ficado com ferimentos graves durante a invasão: $23 \%$ disseram que "sim", de acordo com uma pesquisa da CBS; mais especificamente, $2 \%$ mencionaram ter tido um parente morto e outros $8 \%$ que tiveram um amigo morto. Nas palavras de Montaño (1990, p.7): "os números oficiais das baixas, incluindo soldados e civis, que falavam de 200 a 300 mortos se converteram assim num símbolo do cinismo e a falta de transparência que rodeou a operação Panamá". Em contraposição à história oficial, a projeção de mortos feita a partir dos dados obtidos pelas pesquisas elevou as baixas a um número entre 5 mil e 7 mil pessoas, em sintonia com o que diversos observadores no local comentaram originalmente. Estes dados acabaram tirando grande

\footnotetext{
${ }^{1}$ Uma ênfase parecida nas motivações psicológicas de tipo educativa e auto-assertiva por detrás da disseminação dos resultados de pesquisas políticas foi discutida por Dobson e Robinson (1990) no caso dos estudos de opinião sob a fase final da perestroika na antiga União Soviética. Escrevendo sobre o assunto, eles comentam que " enquanto o partido ainda utiliza as pesquisas para promover suas políticas e demostrar o apoio popular, também se baseia nas mesmas para obter um feedback realista sobre os verdadeiros sentimentos da população. A publicação dos resultados das enquetes fornece aos cidadãos nova informação e os anima a dizer o que realmente pensam. Os cidadãos, agora, citam os resultados das pesquisas para demostrar respaldo a suas próprias demandas" (1990, p. 27).
} 
parte da legitimidade inicial que teve a opção pela redemocratização via intervenção externa, com a qual se tentou vestir a vocação norte-americana pela democracia na região.

Além dos casos centro-americanos comentados, tem sido extensa a maneira como as pesquisas têm operado em favor da democracia sob condições nãodemocráticas na América do Sul. Às vezes, revelando a adesão pública a posições favoráveis à liberalização política das facções reformistas dos governos militares. É como diversos estudantes da transição brasileira entendem o sucesso da abertura de 1974 e sua continuidade nos governos Geisel e Figueiredo (Lamounier, 1990).

Freqüentemente, o impacto democratizador das pesquisas se manifestou mediante caminhos menos diretos, seja alimentando a confiança dos autocratas por apostas políticas cada vez mas arriscadas que acabaram se voltando contra seus interesses ou quando estes estudos informaram aos membros da oposição moderada sobre o respaldo latente da sociedade a uma mobilização em favor da convocação de eleições ou a restauração de outras instituições democráticas. Com efeito, as motivações que levam os ditadores a conduzir e difundir informação de enquetes sobre a opinião pública estiveram sempre longe da intenção de adaptar políticas de governo às necessidades e anseios da população; antes, visavam aperfeiçoar seu comando sobre o clima social e político existente e enxergar recursos para revitalizar a submissão ou fidelidade dos cidadãos ${ }^{2}$. No entanto, podemos identificar um paradoxal efeito democratizador na divulgação das pesquisas de opinião pública, em diversas circunstâncias.

Alguns observadores da política chilena, por exemplo, sugerem que, até um certo ponto, a aposta do General Pinochet no plebiscito de 1988 foi estimulada pelos resultados propícios das pesquisas encomendadas com sigilo para diferentes organizações (Constable \& Valenzuela, 1991, pp.304-305). De modo semelhante, muitos interpretam o compromisso do Sandinismo nicaraguense a realizar eleições livres em Fevereiro de 1990 em função do quadro positivo para seu candidato que quase todas pesquisas insinuavam (Cohen Walker, 1993).

A fluidez intrínseca a estas situações é exemplificada pelo caso uruguaio da convocatória ao plebiscito realizada pela ditadura no ano de $1980 \mathrm{com}$ o intuito de ratificar uma nova constituição, muito mais permeável ao seus interesses corporativos. Na medida em que os números das primeiras pesquisas persuadiram os generais que sua vitória seria segura (e que certa pressão internacional podia ser exercida), as restrições colocadas para a campanha foram flexibilizadas e, assim, as forças democráticas tiveram a oportunidade de se expressar e organizar. Estas liberdades obtidas da noite para o dia, mais a vantagem de toda a oposição civil ter um mesmo objetivo que a manteve coesa, possibilitaram a realização de uma campanha altamente instrutiva sobre o significado e

\footnotetext{
${ }^{2}$ Para uma análise detalhada do uso e abuso das pesquisas políticas sob governos autoritários na América do Sul. ( Smith \& Turner, 1984).
} 
alcance da nova constituição, nutrida em boa parte pela informação recolhida pelas enquetes, graças ao ambiente bem menos repressivo do momento. Os generais, que tinham convocado o plebiscito subitamente de um mês para outro, viram como sua vantagem inicial caía de $48 \%$ para $33 \%$ enquanto que a oposição subia nas preferências de $15 \%$ para $28 \%$. As mesmas pesquisas amplamente divulgadas mostravam a queda de prestígio do governo. Semanas depois nas urnas, a nova constituição dos militares era derrotada (Smith \& Turner, 1984).

Uma última situação pode ser ilustrada novamente pelo caso salvadorenho durante a guerra civil dos anos 80. Tal como nos lembra Cruz Alas (1994, p.28): "as pesquisas de opinião e sua difusão foram permitidas pelos governos nos anos 80 como uma forma de legitimar formalmente o tipo de regime democrático que eles diziam defender". Paradoxalmente, a disseminação dos resultados foi aos poucos questionando a intenção dos militares de ganhar a guerra exclusivamente no campo militar, ao mostrar firmes e substantivas maiorias pronunciando-se sempre em favor da opção das negociações com a guerrilha. Em fins dos anos 80 , esses resultados (entre outras razões) pareciam ter influído sobre o novo governo da ARENA (força política herdeira da ditadura) estimulando-o a trocar sua política militarista por outra de conversações pela paz e desarmamento.

\section{Quando as pesquisas são usadas contra a consolidação democrática}

Mas, as pesquisas de opinião também foram utilizadas para subverter as chances de aprofundamento democrático na região, e até para inviabilizar a própria continuidade da democracia. O caso peruano é paradigmático. Em Abril de 1992, o presidente Fujimori decidiu lançar um auto-golpe fechando todas as outras instituições republicanas e políticas menos o Executivo, argumentando que essa era o que a maioria da população preferia e esperava dele, como o revelavam as pesquisas de opinião. Tal como fora relatado por Catherine Conaghan (1993, pp.2-3): "ao se respaldar nas genuínas frustrações populares sobre o mal funcionamento da democracia peruana, as pesquisas forneceram a Fujimori um raciocínio para romper com a constituição. Com a evidência na mão do apoio popular a suas ações, Fujimori foi capaz de apresentar a violação da constituição como um exercício democrático. As pesquisas foram utilizadas por Fujimori para legitimar seu golpe às instituições e seu agressivo avanço com reformas políticas que aceleraram a desorganização do sistema de partidos, enfraqueceram o legislativo e concentraram ainda mais o poder numa presidência quase imperial".

A experiência peruana ilustra, assim, o potencial para a multiplicação de ações autoritárias baseadas no mal uso das pesquisas onde as mesmas servem, cinicamente, como matéria prima para a desconsolidação da democracia em nome da vontade popular. Contudo, mesmo sob as circunstâncias mencionadas, houve espaço para que as forças democráticas encontrassem algum respaldo nas mesmas pesquisas utilizadas por 
Fujimori. Tal como Conaghan (1993, p.7) comenta: "os opositores ao golpe buscaram criar um discurso alternativo baseado nas pesquisas que enfatizava a natureza contingente do apoio popular a Fujimori e nos "limites" impostos pela própria opinião pública. As pesquisas continuaram a confirmar a presença de um amplo respaldo aos valores democráticos (i.e., respeito pelos direitos humanos, compromisso com as eleições); de modo tal que as pesquisas acabam sendo usadas para promover a idéia que essas normas não podem ser transgredidas pelo governo sem incorrer em custos políticos significativos".

A manipulação das pesquisas para propósitos de propaganda não tem sido apenas um fenômeno que acontece só depois que algum evento ou decisão foi tomada por alguma autoridade ou grupo de poder. Em contextos onde existe uma competição de modelos alternativos por organizar politicamente a sociedade, geralmente caracterizados por uma violenta polarização política, as pesquisas tornam-se parte da munição com que as partes em disputa fazem a guerra psicológica. Os usos de algumas pesquisas pelo situacionismo em El Salvador no final da década de 80 ilustra parcialmente esta afirmação. Tal como Martín-Baró lembrava: "ocasionalmente alguma pesquisa de opinião foi difundida sem informar sobre o método de desenho e sondagem nem qualquer outro dado que nos permitisse avaliar seus resultados. Com a perspectiva da guerra psicológica, um objetivo fundamental do governo salvadorenho tem sido criar imagens que possam ser apresentadas como prova de que a opinião pública coincide com a história oficial. Isso tem dado lugar a um diálogo pouco coerente entre fatos e ficção, viés de interpretação, esforços mal feitos para disfarçar a realidade, exaltação quase ridícula de alguns achados e negação e rejeição sistemática de outros" (Martín-Baro, 1990, p.2).

Outra amostra do possível uso negativo das pesquisas ameaçador do processo de pacificação e democratização na América Central foi dada pela controvérsia sobre a manipulação dos dados pela administração Reagan. De acordo com Bollinger e seus colegas (1988), a difusão de uma onda de pesquisas patrocinadas pelo governo norteamericano na região representou um caso paradigmático de "sintonização" política dos resultados para torná-los consistentes com os interesses dos EUA. As leituras dos dados disseminadas entre a imprensa e a comunidade internacional recriavam um cenário de crise e insegurança tal que deixavam o caminho limpo para justificar a política militarista do governo para a região (vide também Leogrande, 1984 e, para uma visão oposta, Falcoff, 1987). De acordo com esta leitura dos resultados, a ameaça de uma invasão Sandinista na Nicarágua e a expectativa de uma piora no conflito militar entre guerrilhas e ditaduras foram colocadas como os principais problemas de cada país, embora de maneira consistente os estudos indicassem que na frente do pelotão das preocupações das maiorias figuravam tópicos sociais e econômicos. Uma consequência direta deste mal uso político das pesquisas nos países centro-americanos foi a representação incorreta da verdadeira agenda pública e, portanto, um pobre conhecimento político das elites sobre quais eram os assuntos prioritários. 


\section{Conclusões preliminares}

Hoje em dia, as pesquisas políticas e de opinião pública têm se convertido numa característica central ao processo de democratização da América Latina, desvendando suas múltiplas funções. A forma como elas interagem com outros agentes-chaves deste processo (tais como a mídia, as elites locais, e até os poderes internacionais como os EUA) já não pode ser ignorada, nem serve como desculpa para a falta de atenção dada ao assunto.

Esse debate deve ser aprofundado e dele devem participar tanto acadêmicos como profissionais e usuários (de qualquer uma das instituições democráticas, sejam governantes, cidadãos, partidos ou mídia) para entender o aporte à democratização política que as pesquisas fizeram e ainda podem fazer.

\section{BIBLIOGRAFIA}

ALTSCHULER, Bruce. (1982) Keeping a finger on the public pulse, Greenwood Press.

BELTRÁN, Ulysses. (1994) The 1994 Mexican elections: a new electoral order... and a new role for election polling. The Public Perspective, 6(1):12-16, (November/December).

BOLLINGER, William, MONTAÑO, Cristina and LUND, Daniel. (1988) Polling method and political use in undemocratic societies: the case of Central America. Paper presented at the AAPOR/WAPOR Annual Conference. Toronto, Canada (May 19-22).

CANTRIL, Hadley. (1967) The human dimension: experiences in policy research, Rutgers University Press.

CARRASQUERO, José V. and CUPOLO, Marco. (1992) The Venezuelan democratic system and the failed coup attempt. Paper presented at the 1992 WAPOR Annual Conference. St. Petesburgh, Florida (May 18-20).

CHERINGTON, Paul. (1940) Opinion polls as the voice of democracy. Public Opinion Quarterly, 2: 236-238.

CONAGHAN, Catherine. (1993) Polls, political discourse, and the public sphere: the spin on Peru's Fuji-golpe. Paper delivered at the FLACSO-Quito/UCSD-CILAS Conference on New Approaches to Methods and Analysis in Latin America. Quito, Ecuador. (July 29-31) (published in: Peter Smith, ed. Latin America in comparative perspective: new approaches to methods and analysis, Westview).

CONSTABLE, Pamela and VENEZUELA, Arturo. (1991) A nation of enemies: Chile under Pinochet, W.W.Norton \& Co.

CRUZ ALAS, José M. (1994) Las encuestas de opinión pública y el proceso de democratización salvadoreño, Estudios Centroamericanos, 543-544: 21-32.

DOBSON, Richard and ROBINSON, John. (1990) Soviet public opinion research in the age of Perestroika. The Public Perspective, vol.1, 2:26-28, (January/February). 
DONSBACH, Wolfgang. (1995) The role of polls in a Democracy. WAPOR Newsletter, 2: 1 and 14.

FALCOFF, Mark. (1987) Contra-dictions: public and leadership opinion in Central America. Public Opinion, 10: 45-48, (November/December).

GALLUP, George and ERA, Saul. (1940) The pulse of democracy, Simon and Schuster.

GARRETÓN, Manuel, LAGOS, Marta, and MENDEZ, Roberto. (1983) Los chilenos y la democracia. La opinión pública, 1991-1994. Informe 1991, Participa.

GINSBERG, Benjamin. (1986) The captive public: how mass opinion promotes state power, Basic Books.

HERBST, Susan. (1993) Numbered voices: how opinion polling has shaped american politics, University of Chicago Press.

HERRERA, Cheryl et al. (1992) Public opinion and congressional representation. Public Opinion Quarterly, 56(2): 185-205.

KAYANNAH, Dennis. (1981) Public opinion polls. In: BUTLER, David, PENNIMAN, Howard and RANNEY, Austin (eds.) Democracy at the polls: a comparative study of competitive national elections, AEI Press, p.196-215.

LAMOUNIER, Bolívar (org.). (1990) De Geisel a Collor: o Balanço da Transição, Sumaré/IDESP.

LAMOUNIER, Bolívar (org.). (1992) Ouvindo o Brasil, Sumaré/IDESP.

LAMOUNIER, Bolívar. (1994) Brazil: Toward parliamentarism?. In: LINZ, Juan and VALENZUELA, Arturo (eds.) The failure of presidential democracy, The John Hopkins University Press, p.253293.

LEITE, Claudia and SMITH, Peter H. (1992) Social science research on Latin America: a conference report. Working Paper, 2, CILAS/UCSD.

LEOGRANDE, William. (1984) Central America and the polls, Washington Office on Latin America. (May).

LIPPMAN, Walter. (1925) The phantom public, Basic Books.

MARTIN-BARÓ, Ignacio. (1985) La encuesta de opinión pública como instrumento desideologizador, Cuadernos de Psicologia, 1-2, vol.7: 93-108.

MARTIN-BARÓ, Ignacio. (1990) Mass media and public opinion in El Salvador, Interamerican Public Opinion Report, 2 and 12, (January).

McCOY, Jennifer. (1985) The democratic advantage? Perceptions and procedures of economic reform in Uruguay. Paper presented at the 1995 Midwest Political Science Association Meeting. Chicago, Illinois (April 6-8).

McGUIRE, O. R. Col. (1940) The U.S. Constitution and the shekels of silver, Public Opinion Quarterly, 2: 232-235.

MILLER, Warren and STOKES, Donald. (1963) Constituency influence in Congress. American Political Science Review, 57: 45-56.

MONTAÑO, Cristina. (1990) Panamanians welcomed U.S. invasion, Interamerican Public Opinion Report, 7, (Spring).

MYERS, David. (1993) Percepciones de una democracia bajo presión: decadencia inevitable o refundación?. In: SERBIN, Andrés e STAMBOULI, Andre's (eds.) Venezuela bajo presiõn, Nueva Sociedad. 
PAGE, Benjamin et al. (1984) Constituency, party, and representation in Congress, Public Opinion Quarterly, 48: 741-756, (Winter).

ROLL Jr., Charles and CANTRIL, Albert. (1972) Polls. Their use and misuse in politics, Basic Books.

SCOTT, David Clarke. (1983) Public intolerance for graft is toppling Latin leaders, The Christian Science Monitor (June 16): 1 and 4.

SMITH, Brian and TURNER, Frederick. (1984). Survey research in authoritarian regimes: Brazil and the Southern Cone of Latin America. In: WILKIE, James and PERKAL, Adam (eds.) Statistical Abstract of Latin America, v.23, UCLA Press.

WALKER COHEN, C. D. (1993). Polls and politics in Nicaragua. Paper delivered to the ICPSR/Quantitative Research on Latin America 1992 Alumni Reunion. Quito, Ecuador (July 2728).

WELSCH, Friedrich and CARRASQUERO, José V. (1995) Democratic desconsolidation in Venezuela? Performance and normative legitimacy, International Social Science Journal. (December). Também publicado em OPINIÃO PÚBLICA, Vol.V, nº1.

WORCESTER, Robert. (1984) Interview. El Mercurio, September 30.

ZUKIN, Cliff. (1992) Comment on Davis: Yes, but... public opinion is a top-down process, Public Opinion Quarterly, 56: 311-314. 